\title{
Virtual reality sebagai penginduksian emosi negatif
}

\author{
Fachry Ali $^{(1)}$, Novika Grasiaswaty ${ }^{(2)}$, Arif Triman ${ }^{(3)}$ \\ (1),(2),(3)Fakultas Psikologi, Universitas YARSI, Jakarta, Indonesia
}

\begin{abstract}
Emotion is the driving motive of life for humans. The induction of emotions is necessary to understand the behavioural effects and neurobiological determinants of human emotions. The goal of the present work was to examine the effectiveness of virtual reality as a tool to induce negative emotions among a sample of Indonesian participants $(N=20$, with the age ranging between 18 and 25 years old). Emotional manipulation in this research used the immersive video watching method to induce negative emotions, which was measured using the emotional baseline scale. The finding revealed that among the five negative emotions tested, virtual reality significantly induced anger. What can be implied from this finding is that virtual reality can be of use as a reference for the immersive video database in emotion induction research.
\end{abstract}

Keywords: emotion induction, negative emotion, virtual reality

Emosi merupakan motif penggerak kehidupan bagi manusia. Penginduksian emosi diperlukan untuk memahami efek perilaku dan penentu neurobiologis emosi manusia. Penelitian ini bertujuan menguji keefektifan virtual reality sebagai alat menginduksi emosi negatif pada responden di Indonesia. Partisipan penelitian berjumlah 20 mahasiswa dengan rentang usia 18-25 tahun. Manipulasi emosi dalam penelitian ini menggunakan metode menonton video immersive untuk menginduksi emosi negatif yang diukur dengan skala emotional baseline. Hasil penelitian menunjukkan bahwa virtual reality secara signikan mampu menginduksi emosi marah dari lima emosi negatif yang diuji. Implikasinya, virtual reality dapat dijadikan sebagai suatu rujukan database video immersive dalam penelitian penginduksian emosi.

Kata kunci: emosi negatif, induksi emosi, virtual reality

MEDIAPSI, 2021, Vol. 7(1), 63-75, DOI: https://doi.org/10.21776/ub.mps.2021.007.01.7

Received: 05-12-2020. Revised: 29-01-2021. Accepted: 14-02-2021. Published online: 24-06-2021

Handling Editor: Ali Mashuri, Universitas Brawijaya, Malang, Indonesia

*Corresponding author: Fachry Ali, Fakultas Psikologi, Universitas YARSI, Jakarta, Indonesia.

E-mail: fachryali13@gmail.com

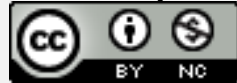

This work is licensed under a Creative Commons Attribution-NonCommercial 4.0 International License.

How to cite this article in accordance with the American Psychological Association (APA) $7^{\text {th }}$ guidelines:

Ali, F., Grasiaswaty, N., \& Triman, A. (2021). Virtual reality sebagai penginduksian emosi negatif. MEDIAPSI, 7(1), 63-75. https://doi.org/10.21776/ub.mps.2021.007.01.7

\section{Pendahuluan}

Di era modern saat ini, banyak penelitian tentang penginduksian emosi melalui beberapa metode. Penginduksian emosi digunakan untuk memahami perilaku dan untuk menilai perubahan fisiologis dan kognitif, yang disinkronkan sebagai respons terhadap stimulus yang diberikan (Cabral dkk., 2018). Penginduksian emosi dapat dilakukan dengan menggunakan sejumlah metode seperti hypnosis, sugesti musik, dan film atau video (Vikan, 2017). Penelitian tentang penginduksian emosi menggunakan film pertama kali dilakukan oleh Gross dan 
Levenson (1995) yang menginduksi emosi negatif (marah, jijik, takut dan sedih) dan positif (bahagia, kepuasan dan kejutan). Penelitian penginduksian emosi negatif dengan metode film juga dilakukan oleh Samson dkk. (2016) yang membuat database film yang dapat menginduksi emosi positif (lucu), emosi negatif (menjijikan), dan emosi campuran. Hasil dari penelitian tersebut menyatakan bahwa film yang diujikan dapat menginduksi emosi positif dan negatif.

Penelitian terbaru menunjukkan bahwa penginduksian emosi telah menggunakan beberapa teknologi dalam metode yang dilakukan, seperti film (Gilman dkk., 2017), televisi (Droulers dkk., 2015), dan imagery techniques (Mills \& D'Mello, 2014) untuk membangkitkan emosi. Hanya saja, masih terdapat kekurangan dari ketiga metode tersebut dalam penginduksian emosi. Pada penelitian Droulers dkk. (2015) metode program televisi masih memiliki keterbatasan yaitu dapat memunculkan variabel lain yang tidak diukur dalam eksperimen untuk membangkitkan emosi. Misalnya, saat diminta untuk menonton program televisi dan diminta untuk memilih salah satu program, partisipan ternyata melakukan tindakan diluar kontrol eksperimen seperti mengganti program televisi. Hal ini dapat menyebabkan munculnya variasi baru dalam eksperimen.

Penelitian lain dengan teknik berbeda dilakukan oleh Mills dan D'Mello (2014) yang menggunakan imagery techniques dengan mengukur aktivitas fisiologis. Salah satu catatan dengan metode ini adalah ketidakmampuan peneliti memanipulasi emosi secara objektif karena aktivitas fisiologis dan perilaku seperti aktivitas elektrodermal dan ekspresi wajah yang kurang mampu memanipulasi emosi secara objektif. Selain itu, Freeman dan Fogg (dalam
Riva dkk., 2007) menyatakan bahwa film, program televisi, dan imagery techniques kurang dapat memanipulasi penginduksian emosi karena media yang digunakan untuk penginduksian emosi hanya sebatas gambar dua dimensi (2D). Oleh karena itu, penginduskian terdahulu kurang bersifat immersed dan kurang maksimal dalam bagian replikasi.

Riva dkk. (2007) mengatakan bahwa virtual reality, yang dalam penelitian ini kami ringkas dengan istilah VR, sebagai media interaktif termutakhir dapat dimanfaatkan untuk membangkitkan emosi. Felnhofer dkk. (2015) mengungkapkan bahwa identik dengan teknologi sebelumnya, VR dapat menginduksi sebagian besar emosi, seperti emosi kegembiraan, kemarahan, kebosanan dan kecemasan. Lebih lanjut, keuntungan utama dari VR adalah bahwa konten virtual dapat menghasilkan replikasi yang lebih kuat dan pengambilan sampel yang lebih dapat menggambarkan hasil penelitian (Li dkk., 2017). Efek emosional dengan menggunakan VR juga diketahui lebih kuat daripada film 2D tradisional (Ding dkk., 2018).

Keuntungan-keuntungan VR ini tidaklah mengherankan karena ada perbedaan mendasar VR dengan teknologi penginduksian emosi sebelumnya. Pada VR, proses penginduksian emosi terjadi lebih kuat karena ada efek yang berbeda dengan teknologi tradisional, yaitu penampil yang dipasang di kepala ataupun tampilan desktop dan platfrom yang sepenuhnya immersive pada saat proses perangsangan emosi (Kim dkk., 2014). Hal ini berbeda untuk teknologi tradisional yang hanya menampilkan gambar 2D pada metode seperti film dan program televisi yang masih kurang dalam replikasi ataupun tidak dapat immersed (Droulers dkk., 2015; Gilman dkk., 2017). Hal ini 
mengakibatkan penginduksian emosi pada VR terasa lebih nyata bagi responden.

Hasil penelitian secara lebih jauh mengungkapkan jika penginduksian emosi dengan menggunakan VR juga berkaitan erat dengan keadaan afektif tertentu (Felnhofer dkk., 2015). Ding dkk. (2018) mengungkapkan bahwa klip VR dapat menginduksi pengalaman emosional negatif dan pada akhirnya berkorelasi dengan reaksi emosional negatif, terutama emosi yang menakutkan.

Penelitian yang dilakukan di beberapa negara di Amerika dan Eropa telah diupayakan untuk mempelajari efektifitas VR dalam menstimulasi emosi. Riva dkk. (2007) melakukan eksperimen VR dengan dua buah video yang berbeda yang dianggap mampu menstimulasi emosi. Eksperimen dilakukan dengan desain repeated dengan menggunakan dua buah video yang mereka buat sendiri, yaitu anxious park vs relaxing park. Penelitian Riva dkk. (2007) menunjukkan hasil bahwa terdapat perubahan yang signifikan pada VR dengan tema the anxious park. Paparan virtual reality dengan tema the anxious park ini mengurangi kebahagiaan dan meningkatkan kesedihan dan kecemasan. Sebaliknya, tema the relaxing park meningkatkan kebahagiaan dan dapat mengurangi kemarahan, kesedihan, dan kecemasan.

Penggunaan media VR juga dilakukan dalam penelitian Felnhofer dkk. (2015) yang menggunakan lima skenario VR dimodelkan dengan tiga dimensi (3D) yang menampilkan lima kondisi mulai dari kegembiraan, kemarahan, kebosanan, kecemasan dan kesedihan. Hasil penelitian Felnhofer dkk. (2015) menunjukkan bahwa VR mampu menginduksi emosi seperti kegembiraan, kemarahan, kebosanan, dan kegelisahan, yang masing-masing memunculkan kondisi afektif yang ditargetkan. Namun, untuk kondisi kesedihan dengan tema taman hujan gagal menghasilkan peringkat kesedihan yang signifikan. Beberapa peneliti (Kim dkk., 2014; Toet dkk., 2016; Ding dkk., 2018) telah melakukan menggunakan media yang berbeda dalam penginduksian emosi yaitu dengan lingkungan virtual. Ding dkk. (2018) menggunakan dua cuplikan film animasi Disney the jungle book, yaitu pada cuplikan monyet dan pada cuplikan ular. Penelitian Ding dkk. (2018) menunjukkan hasil bahwa kelompok yang menggunakan VR mengalami emosi negatif yang lebih kuat daripada kelompok 2D ketika mereka menonton klip video. Kim dkk. (2014) menggunakan lingkungan virtual enam dinding cave dari cave teknologi dengan pengalaman yang sepenuhnya immersive. Hasil penelitian Kim dkk. (2014) menunjukkan bahwa lingkungan virtual mampu membangkitkan gairah emosional yang lebih tinggi daripada layar dekstop. Penelitian Toet dkk. (2016) menggunakan prototypical landscape polder dimana video ini berisi tentang beberapa rumah yang tersebar, dataran rendah di padang rumput yang dikelilingi oleh tanggul, jalan, rel kereta api, kanal, dan tanggul. Hasil penelitian Toet dkk. (2016) menunjukkan bahwa dalam beberapa skema yang ditampilkan memiliki pengaruh yang signifikan untuk membangkitkan gairah emosional. Berdasarkan pemaparan di atas dapat disimpulkan bahwa VR memiliki pengaruh yang cukup meyakinkan dalam menginduksi emosi negatif dengan menggunakan berbagai macam media baik taman maupun cuplikan film dan tayangan video yang diberikan.

Penerapan penelitian VR lebih jauh dilakukan oleh Li dkk. (2017) dengan 
menggunakan media yang berbeda yaitu video. Dalam penelitian tersebut, mereka membuat database video yang telah diujikan terhadap 95 partisipan yang terdiri dari 73 klip video immersive. Hasil dari penelitian $\mathrm{Li}$ dkk. (2017) menunjukkan bahwa 73 klip video immersive memiliki rangsangan yang bervariasi cukup baik di sepanjang dimensi valensi dan gairah. Hal ini menunjukan bahwa setiap video dapat membangkitkan emosi. Database video pada penelitian $\mathrm{Li}$ dkk. (2017) telah dirujuk 12 kali dan digunakan dalam beberapa penelitian tentang emosi, seperti penelitian Colombo dkk. (2019) yang menyatakan bahwa Environment Virtual (ER) atau lingkungan virtual dapat menginduksi emosi. Kemudian Ciresi dkk. (2018) meneliti tentang pemahaman dan diagnosis gangguan mood dan emosional pada dataset kesehatan mental berbasis VR. Namun dari 12 rujukan tersebut, tidak ada satupun penelitian yang dilakukan di Indonesia ataupun menggunakan sampel penelitan dengan karakteristik Indonesia.

Di Indonesia, penelitian menggunakan media teknologi VR pada umumnya lebih banyak berkembang pada penelitian teknologi informasi. Sebagai contoh, penelitian yang dilakukan oleh Wardijono dkk. (2015) menguji pengembangan model grafik 3D Monumen Nasional dan lingkungan sekitarnya dengan teknologi VR berbasis web. Hasil penelitian Wardijono dkk. (2015) menunjukkan bahwa suatu model 3D dari Monumen Nasional dan objek yang berada di lingkungan sekitarnya bisa ditampilkan melalui web browser serta website tentang Monumen Nasional.

Penelitian mengenai VR pada bidang psikologi hanya sebatas media terapi. Penelitian yang dilakukan oleh Tsani (2019) misalnya telah menggunakan media VR sebagai terapi archophobia. Hasil penelitian Tsani (2019) menunjukkan bahwa berdasarkan hasil pegujian pada aplikasi simulasi 3D VR, aplikasi dapat menjadi terapi archophobia dengan tambahan beberapa elemen agar dapat berfungsi dengan baik. Berdasarkan temuan ini, peneliti ingin mengeksplorasi lebih dalam lagi terkait keefektifan VR dalam bidang psikologi khusunya dalam penginduksian emosi pada responden di indonesia.

Penelitian tentang penginduksian emosi di Indonesia masih menggunakan media audiovisual, video dan imagery techniques. Penelitian Rumpa dkk. (2018) sebagai contoh menggunakan media audiovisual atau stimuli video dalam pembangkitan emosi pada karakteristik penelitian di Indonesia. Begitu pula dengan penelitian yang dilakukan oleh Wijayanti dan Ahmad (2014) yang menggunakan metode imagery techniques dengan cara mengingat peristiwa yang menyenangkan untuk menginduksi emosi positif sedangkan untuk emosi negatif subjek diminta untuk mengingat pengalaman yang menyedihkan. Penelitian yang dilakukan Wijayanti dan Ahmad (2014) tidak dapat menjawab hipotesa yang diujikan karena memiliki variabel sekunder yang tidak dikontrol oleh peneliti yaitu variabel kognitif dalam metode imagery techniques, yang dapat memberikan peran pada respon emosional. Secara umum, metode-metode yang digunakan pada penelitian sebelumnya masih memiliki keterbatasan dalam menginduksi emosi. Berdasarkan paparan di atas, penelitian ini bertujuan untuk mengetahui efektifitas VR sebagai penginduksi emosi negatif pada responden di Indonesia. 


\section{Metode}

\section{Partisipan dan Desain Penelitian}

Jumlah partisipan dalam penelitian ini adalah sebanyak 20 partisipan yang terdiri dari 10 orang laki-laki dan 10 orang perempuan yang berstatus sebagai mahasiswa aktif di Universitas YARSI. Usia partisipan memiliki nilai rata-rata atau $M=20.80$ dan deviasi standar atau $S D=1.40$, dengan usia yang merentang 18 sampai dengan 25 tahun. Penelitian ini menggunakan metode eksperimental dengan desain within subject one-group pretest-posttest. Tipe penelitian yang digunakan adalah controlled laboratory experiment dimana penelitian dilakukan pada keadaan tidak alamiah karena peneliti sudah mengontrol variabel sekunder dengan ketat (Seniati dkk., 2015).

\section{Prosedur dan Pengukuran}

Penelitian ini menggunakan dua alat ukur yaitu self-assessment manikin (SAM) untuk mengukur valensi emosi, emotional baseline untuk mengukur emosi negatif yang dirasakan dan klip video immersive untuk menginduksi emosi negatif.

Dalam penelitian ini, sebelum dan sesudah diberikan induksi emosi, partisipan diminta untuk memberikan penilaian terhadap valensi emosi yang dirasakan menggunakan penilaian self-assessment manikin (SAM) dari Lang (1980). SAM menunjukkan serangkaian gambar grafis yang berkisar di sepanjang dimensi valensi dan gairah. Ekspresi gambargambar ini bervariasi dalam skala kontinum. Skala SAM untuk valensi menunjukkan sosok sedih dan tidak bahagia di satu sisi, dan sosok tersenyum dan bahagia di sisi lain. Dalam penelitian ini, penilaian self-assessment manikin diubah menjadi gambar emoticon agar dapat dipahami oleh responden, sebagaimana ditampilkan pada Gambar 1 di bawah ini.

Gambar 1. Penilaian SAM.

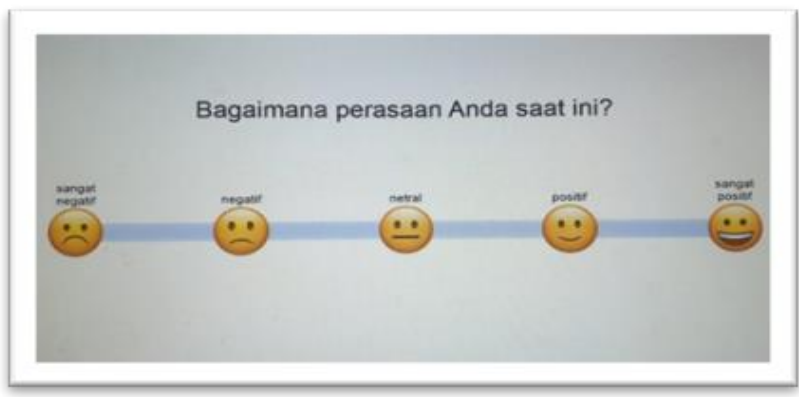

Dalam penelitian ini, sebelum dan sesudah diberikan induksi emosi, partisipan diberikan skala emotional baseline terkait dengan emosi yang dirasakan partisipan pada saat itu. Haase dkk. (2012) menyebutkan bahwa partisipan menginformasikan seberapa kuat emosi yang mereka rasakan sebagairespon terhadap sembilan emosi yang diberikan dalam skala satu kali diawal sesi. Emosi tersebut antara lain humor, marah, senang, kasih sayang, jijik, antusias atau gembira, takut, sedih, dan terkejut. Skala penilaian untuk setiap emosi berkisar dari 0 (tidak mengalami emosi sama sekali) hingga 8 (merasakan emosi dengan sangat kuat) (Haase dkk., 2012). Pada penelitian ini skala penilaian emotional baseline diubah menjadi model slider seperti pada Gambar 2.

Gambar 2. Emotional Baseline Slider.

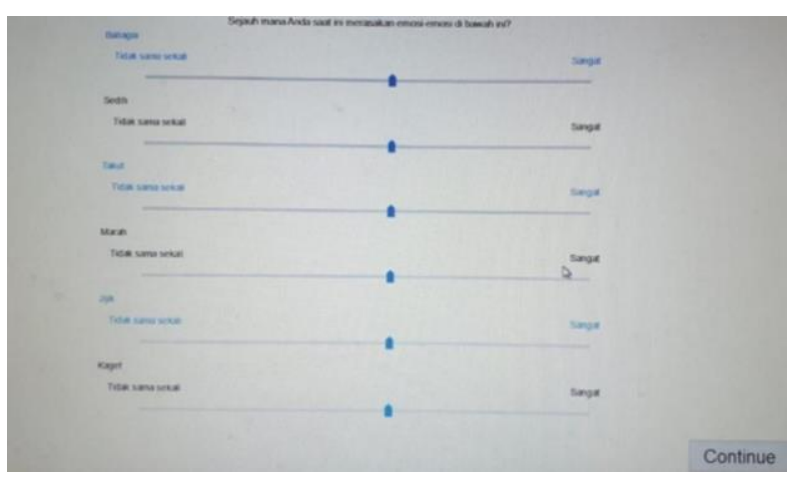

Peserta melihat klip immersive VR melalui Oculus Rift CV1 display yang dipasang di kepala (HMD). The Oculus Rift 
memiliki resolusi $1080 \times 200$ piksel, bidang tampilan 110 dan kecepatan refresh $90 \mathrm{~Hz}$. Teknologi pelacakan latensi rendah untuk menentukan posisi relatif sesuai dari kepala partisipan dan menyesuaikan pandangannya tentang video immersive. Peserta berinteraksi dengan permintaan di layar dan memberi peringkat video menggunakan remote Oculus Rift. Perangkat lunak Vizard 5 digunakan untuk memprogram sistem peringkat. Perangkat lunak ini berjalan pada komputer Intel i7 $3.6 \mathrm{GHz}$ dengan grafis Nvidia GTX 1080. Bobo Z5 virtual reality dengan resolusi 720 x 1080 untuk ponsel ukuran 5 inc dengan sistem operasi Android/iOS/Windows Mobile, yang memiliki format media WMV, MP3, MP4 AVI, dengan bahan ABS berdimensi 15 $\mathrm{x} 9 \mathrm{x} 8 \mathrm{~cm}$.

Klip video immersive adalah klip video yang dapat memberikan perasaan seolah-olah berada pada kondisi yang nyata pada saat menonton video. Peneliti menggunakan klip video immersive yang terdapat di dalam database penelitian Li dkk. (2017). Klip video terebut telah diujikan kepada 95 partisipan dan telah diklasifikasikan menjadi 3 kategori, yaitu rendah, sedang, dan tinggi serta dijadikan database sebagai rujukan penelitian penginduksian emosi menggunkan VR. Peneliti mengevaluasi klip video dan putaran seleksi berikutnya dilakukan berdasarkan tiga kriteria yang ditetapkan. Pertama, klip harus memiliki durasi yang relatif pendek. Hal ini sangat penting karena klip yang berdurasi lebih panjang dapat menyebabkan kelelahan dan mual di antara peserta. Kedua, klip-klip immersive harus dapat dimengerti sendiri tanpa perlu penjelasan lebih lanjut. Ketiga, klip-klip immersive seharusnya cenderung menginduksi valensi, dengan tujuan untuk mendapatkan penyebaran video yang baik yang akan bervariasi di seluruh dimensi.

Pemilihan video yang digunakan juga melewati berbagai tahapan dimana video diuji pada beberapa orang untuk menilai kelayakannya pada responden di Indonesia. Pemilihan video juga didasari oleh penelitian sebelumnya yang dilakukan oleh Rumpa dkk. (2018). Dalam penelitian tersebut, database video $2 \mathrm{D}$ telah diuji dengan tema-tema yang menunjukan video yang dapat menginduksi emosi seperti emosi marah, sedih, jijik dan kaget. Emosi yang diterima di Indonesia cenderung memiliki tema adegan yang bisa memberi kesan kasih sayang, musik sedih sebagai latar belakang, adegan yang mengandung ketidakadilan, adegan yang dapat memicu mual, ketidaknyamanan dan geli, serta adegan yang berisi peningkatan volume.

Berdasarkan hasil diskusi oleh tim penelitian, akhirnya terpilih 10 klip video immersive untuk penelitian ini dengan tema berdarah dan keras seperti korban serangan bom atom, seorang wanita disandera dengan pisau di tenggorokannya dan berada pada sel pengasingan militer. Masing-masing klip memiliki durasi berkisar antara 29 hingga 668 detik, yang memiliki tingkat aurosal tinggi dan valensi paling rendah untuk menginduksi emosi negatif. Sumber klip mencakup kontak pribadi dan pencarian internet di situs web seperti YouTube, Vrideo, dan Facebook. Database video immersive yang digunakan dapat dilihat pada Tabel 2 pada bagian apendiks.

\section{Prosedur dan pengukuran}

Pengambilan data pada penelitian ini dilakukan di laboratorium eksperimen Fakultas Psikologi Universitas YARSI dan cafe Terasa Cempaka Putih. Pengambilan data dilakukan pada dua tempat dikarenakan adanya pandemi Covid-19. Awalnya, pengambilan data dilakukan di Laboratorium eksperimen Fakultas Psikologi Universitas YARSI. Namun, karena pemberlakuan pembatasan sosial berskala besar (PSBB) di Jakarta menyebabkan kampus ditutup sementara, peneliti mencari tempat lain untuk 
pengambilan data. Adapun tahapan pengambilan data yang dilakukan oleh peneliti diawali dengan pemberian lembar informasi, informed consent, dan lembar indentitas. Selanjutnya adalah pengukuran emosi. Tahapan berikutnya adalah induksi emosi, yng dilanjutkan dengan pengukuran pemeriksaan manipulasi. Tahapan berikutnya adalah terapi relaksasi kemudian debriefing dan pemberian reward, yang diakhiri dengan pengukuran emosi.

\section{Hasil}

Dalam penelitian ini data yang diperoleh dianalisis menggunakan uji paired sampel $t$-test untuk data yang terdistribusi normal dan menggunakan Wilcoxon signedrank test pada data yang tidak terdistribusi normal dengan software JASP 0.14 for Windows.

Berdasarkan hasil pengambilan data yang telah dilakukan, jumlah partisipan penelitian yang memenuhi karakteristik penelitian sebanyak 20 partisipan. Dengan perbandingan jenis kelamin laki-laki dan perempuan seimbang, yaitu $50 \%$. Kemudian untuk usia partisipan memiliki nilaib $M=$ 20.8 dan $S D=1.4$, dengan rentang usia 18 sampai 25 tahun.

Terdapat tiga kategori rentang valensi, yaitu nilai valensi $0-2.9$ yang cenderung menginduksi emosi negatif, nilai valensi 3 yang bersifat netral, dan nilai valensi $3.1-5$ yang cenderung mengindusksi emosi positif. Berdasarkan Gambar 3, bisa disimpulkan bahwa video $1,4,5,6,8$, dan 9 memiliki nilai valensi $M=2, M=2.25, M=2.5$, dan $M=$ 2.75 setelah dilakukan eksperimen. Hal ini berarti bahwa video tersebut cenderung menginduksi emosi negatif, karena berada pada rentang nilai valensi 0 - 2.9. Video 3 memiliki nilai valensi $M=3$ setelah dilakukan eksperimen. Hal ini menunjukan bahwa pada video tersebut cenderung netral, karena berada pada rentang nilai valensi 3 . Sementara itu, video 2,7 , dan 10 memiliki nilai valensi $M=3.25$ dan $M=3.5$ setelah dilakukan eksperimen. Hal ini berarti bahwa video tersebut cenderung menginduksi emosi positif, karena berada pada rentang nilai valensi $3.1-5$.

Gambar 3. Perbandingan Nilai Baseline dengan Eksperimen Valensi Emosi.

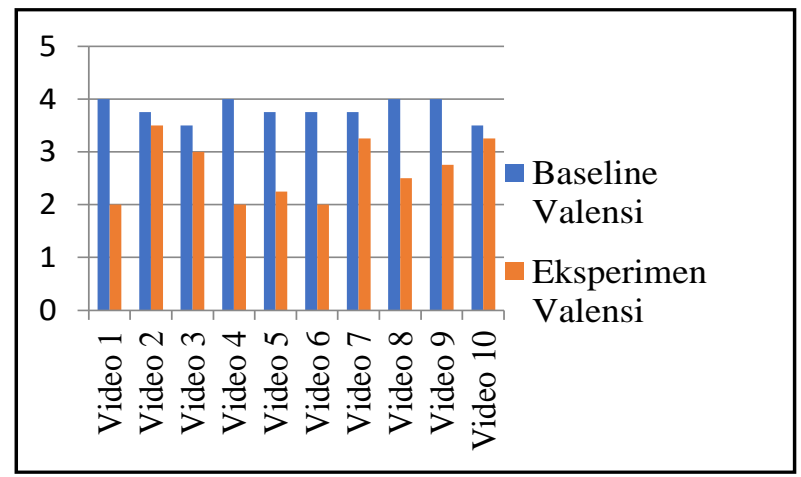

Tabel 1. Hasil Uji Paired Sample T-Test.

\begin{tabular}{lcccc}
\hline \multicolumn{1}{c}{ Jenis emosi } & $t$ & $d f$ & $p$ & Mean difference \\
\hline Valensi emosi & 136.00 & - & $<.001$ & - \\
Emosi marah & -2.404 & 18 & .027 & -1.82 \\
Emosi takut & -1.408 & 19 & .175 & -1.28 \\
Emosi jijik & -1.113 & 19 & .279 & -0.70 \\
Emosi sedih & -1.550 & 19 & .138 & -1.10 \\
Emosi kaget & -2.009 & 19 & .059 & -1.36 \\
\hline
\end{tabular}

Keterangan. $t=$ nilai paired sample $t$-test,$d f=$ derajat bebas, $p=$ nilai signifikansi, mean difference $=$ perbedaan nilai rata-rata. 


\section{Diskusi}

Tujuan penelitian ini adalah menguji pengaruh virtual reality (VE) terhadap emosi negatif. Hasil penelitian menunjukkan bahwa VR dapat menginduksi emosi negatif seperti emosi marah, takut, kaget sedih, dan jijik. Valensi emosi dan emosi marah memperoleh hasil yang signifikan dalam menginduksi emosi sebelum dan setelah pemberian eksperimen.

Hal ini dapat dilihat dari nilai rata-rata dan deviasi standar masing masing video, dimana video pertama dan kedua cenderung menginduksi emosi marah. Sementara itu, video ketiga cenderung menginduksi emosi jijik, video keempat emosi sedih, video kelima emosi takut, video keenam emosi marah, video ketujuh emosi sedih, video kedelapan emosi takut, video kesembilan emosi sedih serta kaget, dan video kesepuluh emosi sedih.

Temuan di atas sejalan dengan penelitian sebelumnya yang dilakukan oleh $\mathrm{Li}$ dkk. (2017) yang membuat sebuah database video immersive dalam satuan klasifikasi emosi. Pada penelitian Li dkk. (2017) terdapat 3 kategori pengklasifiksian dari 73 video immersive yaitu rendah, sedang dan tinggi. Tingkatan rendah cenderung menginduksi emosi negatif dengan nilai valensi 2.18 - 5.36, tingkatan sedang cenderung netral dan menginduksi sebagian emosi positif dengan dengan nilai valensi 5.36 - 6.27. Tingkatan tinggi cenderung menginduksi emosi positif dengan valensi 6.36 - 7.77.

Sepuluh video immersive yang digunakan dalam penelitian ini, dengan demikian bisa dikategorisasikan ke dalam tingkatan rendah yang berada pada rentang nilai valensi antara 2.18 - 5.36. Video immersive yang terpilih tersebut cenderung menginduksi emosi negatif dengan tema-tema seperti database yang telah dibuat dan diujikan kembali pada responden Indonesia.

Kemudian, uji Wilcoxon signed-rank test menunjukkan bahwa valensi emosi berbeda secara signifikan antara sebelum dan sesudah pemberian eksperimen. Berdasarkan uji paired sampel t-test ditemukan bahwa dari keenam emosi yang diujikan hanya emosi marah yang memiliki perbedaan signifikan antara sebelum dan sesudah pemberian eksperimen.

Temuan di atas menunjukan bahwa VR dapat menginduksi emosi negatif. Sesuai dengan penelitian Li dkk. (2017), beberapa emosi negatif yang tertangkap karena video yang ditayangkan tidak dapat diterima oleh budaya, seperti tema-tema yang berdarah atau keras, korban serangan yang wajahnya dimutilasi, atau seorang wanita disandera dengan pisau di tenggorokannya. Hal ini juga dijelaskan dalam penelitian Felnhofer dkk. (2015) dimana dari beberapa emosi yang diujikan video immersive hanya membangkitkan beberapa emosi seperti emosi kegembiraan, kemarahan, kebosanan, dan kecemasan. Alasannya, beberapa tema video terkesan membosankan bagi partisipan yang mengakibatkan gagal menghasilkan peringkat kesedihan yang signifikan.

Felnhofer dkk. (2015) menyatakan bahwa hal yang mempengaruhi dalam penginduksian emosi adalah terkait adanya variabel sekunder seperti pencahayan dan kebisingan dalam pemutaran video VR. Hal ini dikarenakan adanya perubahan pada kondisi pencahayaan VR (terang dan gelap) dan suara. Argumentasi ini didukung oleh penelitian yang berasal dari bidang psikologi lingkungan. Penelitian-penelitian tersebut menunjukkan bahwa orang-orang menunjukkan preferensi yang berbeda untuk lingkungan terang dan gelap dan menunjukan 
bahwa lingkungan dengan pencahayaan berbeda juga dapat menghasilkan penilaian afektif yang berbeda (Hanyu, 2000; Beute \& de Kort, 2013). Hal ini juga dijelaskan dalam penelitian Miller (2005) yang menunjukkan bahwa kebisingan yang tidak menyenangkan secara terus-menerus menghasilkan frustrasi dan kemarahan.

Riva dkk. (2007) menyatakan bahwa taman VR dapat memunculkan emosi tertentu dan tidak ada induksi emosi yang dialami dari kondisi netral yang diberikan. Lebih lanjut, Riva dkk. (2007) menyatakan bahwa terdapat dua hal yang mempengaruhi hasil yang signifikan dalam penelitiannya yaitu ukuran sampel eksperimental terbatas dan pengukuran kondisi emosional hanya menggunakan self-report questionnaires. Hal ini mempengaruhi beberapa analisis terutama untuk analisis regresi linier bertingkat yang akan mendapatkan kekuatan statistik yang rendah. Bahkan jika alat penilaian yang digunakan divalidasi dan diuji secara efektif dalam konteks yang berbeda, penggunaan indeks fisiologis dapat membantu dalam memperoleh gambaran yang lebih lengkap tentang respon emosional pengguna. Lebih jauh, pemanfaatan VR sebagai alat psikoterapi dapat digunakan untuk mengetahui bagaimana individu dapat merespon emosi negatif yang dirasakan setelah diinduksi. Beberapa literatur menyebutkan psikoterapi dapat menurunkan skor kecemasan jangka pendek dan juga dapat menurukan skor depresi (Kurniawan \& Noviza, 2018; Sudiyanto, 2005).

Penelitian ini memiliki kelebihan dan kekurangan yang dapat menjadi pertimbangan bagi penelitian selanjutnya. Kelebihan dari penelitian ini adalah penginduksian emosi pertama yang menggunakan virtual reality atau VR dalam bidang psikologi. Selanjutnya, kelebihan dari penelitian ini adalah pengujian beberapa emosi spesifik dan pemberian database video virtual reality yang sesuai dengan budaya Indonesia. Kekurangan dari penelitian ini adalah pembagian pemutaran video yang mana satu partisipan menilai dua video yang menyebabkan masih kurang respresentatif dalam penggambaran hasil. Selain itu, kekurangan dalam penelitian ini berakitan dengan tidak optimalnya kontrol terhadap variabel-variabel sekunder misalnya pencahayaan, tingkat kebisingan, dan sebagainya. Kekurangan berikutnya dalam penelitian ini berkaitan dengan pengolahan data, dimana pada penelitian ini pengolahan data menggunakan paired sampel T-test yang menyebabkan kurang terhitung varians dalam penelitian ini.

Untuk menutupi kekurangan di atas, penelitian lanjutan disarankan untuk melibatkan sampel yang lebih besar agar hasil yang diperoleh dapat lebih menggambarkan hasil penelitian. Saran kedua, penelitian lanjutan melakukan kontrol terhadap variabel sekunder seperti motion sickness, pencahayaan, intensitas kebisingan, dan sebagainya. Saran terakhir, penelitian lanjutan perlu melakukan pengolahan data menggunakan desain faktorial agar dapat varians yang ada dalam penelitian bisa lebih dikendalikan.

\section{Kesimpulan}

Virtual reality sebagai sebuah pengalaman yang tidak sama dengan kehidupan nyata dalam penelitian ini terbukti secara signifikan menimbulkan emosi marah. Temuan ini memberikan sebuah implikasi bahwa stimulasi dunia maya di era serba digital saat ini berpengaruh kuat dalam menentukan emosi negatif yang benar-benar 
dirasakan oleh individu, terutama emosi negatif dalam bentuk amarah.

\section{Daftar Pustaka}

Beute, F., \& de Kort, Y. A. W. (2013). Let the sun shine! Measuring explicit and implicit preference for environments differing in naturalness, weather type and brightness. Journal of Environmental Psychology, 36, 162-178. https://doi.org/10.1016/j.jenvp.2013.07.0 16

Cabral, J. C. C., Tavares, P. D. S., Weydmann, G. J., das Neves, V. T., \& de Almeida, R. M. M. (2018). Eliciting negative affects using film clips and reallife methods. Psychological reports, 121(3), 527-547. https://doi.org/10.1177/00332941177308 44

Ciresi, S., Hewitt, J., \& Raterink, C. (2018). Anxiety disorder prediction from virtual reality head movements [Project report]. http://cs229.stanford.edu/proj2018/report 1241.pdf

Colombo, D., Fernández-álvarez, J., Palacios, A. G., Cipresso, P., Botella, C., \& Riva, G. (2019). New technologies for the understanding, assessment, and intervention of emotion regulation. Frontiers in Psychology, 10: 1261. https://doi.org/10.3389/fpsyg.2019.0126 1

Ding, N., Zhou, W., \& Fung, A. Y. (2018). Emotional effect of cinematic VR compared with traditional 2D film. Telematics and Informatics, 35(6), 1572-1579. https://doi.org/10.1016/j.tele.2018.04.00 3

Droulers, O., Badie, S. L., \& Malek, F. (2015). Age-related differences in emotion regulation within the context of sad and happy tv programs. Psychology \& Marketing, 32, 795-807. https://doi.org/10.1002/mar.20819

Felnhofer, A., Kothgassner, O. D., Schmidt, M., Heinzle, A., Beutl, L., Hlavacs, H., \& Kryspin-exner, I. (2015). Is virtual reality emotionally arousing? Investigating five emotion inducing virtual park scenarios. Journal of Human Computer Studies, 82, 48-56. https://doi.org/10.1016/j.ijhcs.2015.05.0 04

Gilman, T. L., Shaheen, R., Nylocks, K. M., Halachoff, D., Chapman, J., Flynn, J. J., Matt, L. M., \& Coifman, K. G. (2017). A film set for the elicitation of emotion in research: A comprehensive catalog derived from four decades of investigation. Behavior Research Methods, 49(6), 20612082. https://doi.org/10.3758/s13428016-0842-x

Gross, J. J., \& Levenson, R. W. (1995). Emotion elicitation using films. Cognition and Emotion, 9(1), 87108. https://doi.org/10.1080/0269993950 8408966

Haase, C. M., Seider, B. H., Shiota, M. N., \& Levenson, R. W. (2012). Anger and sadness in response to an emotionally neutral film: Evidence for age-specific associations with well-being. Psychology and Aging, 27(2), 305317. https://doi.org/10.1037/a0024959

Hanyu, K. (2000). Visual properties and affective appraisals in residential areas in daylight. Journal of Environmental Psychology, 20(3), 273-284. https://doi.org/10.1006/jevp.1999.0163

Tsani, A. T. (2019). Analisis pembuatan simulasi $3 d$ virtual reality sebagai 
media.

INA-Rxiv.

https://doi.org/10.31227/osf.io/pb2ua

Kim, K., Rosenthal, M. Z., Zielinski, D. J., \& Brady, R. (2014). Effects of virtual environment platforms on emotional responses. Computer Methods and Programs in Biomedicine, 113(3), 882893.

https://doi.org/10.1016/j.cmpb.2013.12.0 24

Kurniawan, Y., \& Noviza, N. (2017). Psikoterapi interpersonal untuk menurunkan gejala depresi pada perempuan korban kekerasan dalam rumah tangga. INSAN Jurnal Psikologi Dan Kesehatan Mental, 2(2), 96-102. http://doi.org/10.20473/jpkm.V2I22017. 96-102

Lang, P. J. (1980). Behavioral treatment and bio-behavioral assessment. In J. B. Sidowski, J. H. Johnson, \& T. A. Williams (Eds.), Technology in mental health care delivery systems (pp. 119167). Ablex.

Li, B. J., Bailenson, J. N., Pines, A., Greenleaf, W. J., \& Williams, L. M. (2017). A public database of immersive VR videos with corresponding ratings of arousal, valence, and correlations between head movements and self report measures. Frontiers in Psychology, 8: 2116.

https://doi.org/10.3389/fpsyg.2017.0211 6

Miller, J. D. (2005). Effects of noise on people. Journal of the Acoustical Society of America, 56(3), 729-764. https://doi.org/10.1121/1.1903322

Mills, C., \& D’Mello, S. (2014). On the validity of the autobiographical emotional memory task for emotion induction. PLoS ONE, 9(4), Article e95837.

https://doi.org/10.1371/journal.pone.0095 837

Riva, G., Mantovani, F., Capideville, C. S., Preziosa, A., Morganti, F., Villani, D., ... Alcañiz, M. (2007). Affective interactions using virtual reality: The link between presence and emotions. Cyberpsychology and Behavior, 10(1), 45-56.

https://doi.org/10.1089/cpb.2006.9993

Rumpa, L. D., Tulak, H., Thadius, Y., Linggih, I. K., \& Karuru, P. (2018). Validasi stimuli audiovisual emosi sedih manusia: Studi preliminari e-health monitoring system. Journal Dynamic Saint, $\quad 2(1), \quad 1-3$. https://doi.org/10.47178/dynamicsaint.v2 i1.307

Samson, A. C., Kreibig, S. D., Soderstrom, B., Wade, A. A., \& Gross, J. J. (2016). Eliciting positive, negative and mixed emotional states: A film library for affective scientists. Cognition and Emotion, 30(5), 827-856. https://doi.org/10.1080/02699931.2015.1 031089

Seniati, L., Yulianto, A., \& Setiadi, B. N. (2015). Psikologi eksperimen. PT. Indeks.

Sudiyanto, A. (2005). Keefektifan psikoterapi untuk menurunkan skor kecemasan pasien gangguan anxietas. Jurnal Berkala Ilmiah Berkala Psikologi, 7(2), 158-170.

https://doi.org/10.23917/indigenous.v0i0 .4643

Toet, A., Houtkamp, J. M., \& Vreugdenhil, P. E. (2016). Effects of personal relevance and simulated darkness on the affective appraisal of a virtual environment. PeerJ, $\quad 4, \quad$ Article 
e1743. https://doi.org/10.7717/peerj.174 3

Vikan, A. (2017). A fast road to the study of emotions. Springer International Publishing.

Wardijono, B. A., Hendajani, F., Sudiro, S. A., \& Ramadhani, A. I. (2015). Pengembangan model grafik 3 dimensi monumen nasional dan lingkungan sekitarnya dengan teknologi virtual reality berbasis web. Prosiding Seminar
Nasional Sians dan Teknologi, 1-6. https://jurnal.umj.ac.id/index.php/semnas tek/article/viewFile/536/502

Wijayanti, Y. T., \& Ahmad, A. (2014). Pengaruh induksi emosi terhadap keputusan membeli produk. Jurnal Komunikasi PROFETIK, 7, 45-56. http://ejournal.uinsuka.ac.id/isoshum/profetik/article/view/ 1114/1027 


\section{Apendiks}

Tabel 2. Database Video Immersive.

Data Base Video Emosi Negatif

\begin{tabular}{|c|c|c|c|c|c|}
\hline Kode & Judul & Deskripsi Video & Jenis & Durasi & Valensi \\
\hline VN 1 & $\begin{array}{l}\text { No Mires a Otro Lado' } \\
\text { desde la óptica de un } \\
\text { testigo }\end{array}$ & $\begin{array}{l}\text { Video yang direkam dalam teknologi } 360^{\circ} \text { dan } \\
\text { memungkinkan respoden untuk menyaksikan } \\
\text { berbagai situasi pelecehan: psikologis, kekerasan } \\
\text { gender di kalangan anak muda, dan kekerasan fisik }\end{array}$ & Marah & $1: 40$ & 2 \\
\hline VN 2 & $360 \mid$ It & $\begin{array}{l}\text { Video ini berisi tentang cuplikan film IT dalam } \\
\text { teknologi } 360^{\circ}\end{array}$ & Takut & $4: 34$ & 3.5 \\
\hline VN 3 & Inside a bee hive & $\begin{array}{l}\text { Peternak lebah lokal Jay Williams menempatkan } \\
\text { kamera } 360 \text { di dalam salah satu sarang lebahnya di } \\
\text { Peternakan lebah di Franklin Farm tempat dia } \\
\text { memelihara lebih dari } 2 \text { juta lebah }\end{array}$ & Jijik & $0: 44$ & 3 \\
\hline VN 4 & $\begin{array}{l}\text { First Ever War Zone in } \\
360^{\circ} \text { Virtual Reality - } \\
\text { Welcome to Aleppo }\end{array}$ & $\begin{array}{l}\text { Film pendek imersif ini - film VR pertama dari zona } \\
\text { perang - dibuat di jalanan Aleppo yang dilanda } \\
\text { perang yang dimuat dalam teknologi } 360^{\circ}\end{array}$ & Sedih & $3: 04$ & 2 \\
\hline VN 5 & $\begin{array}{l}360 \text { Video } \mid \text { VR } \mid \\
\text { FNAF }\end{array}$ & $\begin{array}{l}\text { Video ini berisi tentang responden berada dalam } \\
\text { ruangan Fazbear's Family Pizzeria yang gelap dan } \\
\text { menyeramkan dalam teknologi } 360^{\circ}\end{array}$ & Takut & 4:08 & 2.2 \\
\hline VN 6 & Bullying 360 RV & $\begin{array}{l}\text { Bullying } 360 \text { RV mengusulkan serangkaian loka } \\
\text { karya di mana, melalui teknologi Virtual Reality dan } \\
\text { Emotional Intelligence, setiap agen yang terlibat } \\
\text { mengadopsi masing-masing peran yang terjadi } \\
\text { dalam konteks pelecehan, dengan tujuan empati. }\end{array}$ & Marah & $6: 53$ & 2 \\
\hline VN 7 & $\begin{array}{l}360^{\circ} \text { VR VIDEO - } \\
\text { Distracted Driver in } \\
\text { First Person- Fatal Car } \\
\text { Crash Accident in } \\
\text { Jaguar }\end{array}$ & $\begin{array}{l}\text { Video ini berisi tentang seorang pengendara mobil } \\
\text { mengalami disktraksi saat menyetir yang } \\
\text { menyebabkan kecelakaan yang dimuat dalam } \\
\text { teknologi } 360^{\circ}\end{array}$ & Sedih & $2: 37$ & 3.2 \\
\hline VN 8 & $\begin{array}{l}\text { SYIRIK! A } 360^{\circ} \\
\text { Horror Short Film }\end{array}$ & $\begin{array}{l}\text { Video ini berisi tentang seseorangmendatangi } \\
\text { paranormal dengan segala hal mistis didalamnya } \\
\text { yang dimuat dalam teknologi } 360^{\circ}\end{array}$ & Takut & $3: 07$ & 2.5 \\
\hline VN 9 & Stop Pesten & $\begin{array}{l}\text { Video ini berisi tentang perundungan terhadap } \\
\text { seorang anak, yang dapat membuat empati } \\
\text { responden yang dimuat dalam teknologi } 360^{\circ}\end{array}$ & Marah & $0: 48$ & 2.7 \\
\hline $\begin{array}{l}\text { VN } \\
10\end{array}$ & $\begin{array}{l}\text { Agony in a } \\
\text { Venezuelan Mental } \\
\text { Health Hospital | The } \\
\text { Daily } 360 \mid \text { The New } \\
\text { York Times }\end{array}$ & $\begin{array}{l}\text { Video ini berisi tentang berada di dalam rumah sakit } \\
\text { jiwa di Venezuela yang kekurangan makanan dan } \\
\text { obat-obatan menyiksa pasien kejiwaan yang dimuat } \\
\text { dalam teknologi } 360^{\circ}\end{array}$ & Sedih & $3: 31$ & 3.2 \\
\hline
\end{tabular}

